\section{Promotion of prehospital emergency care through clinical decision support systems: opportunities and challenges}

\author{
Azadeh Bashiri', Behrouz Alizadeh Savareh ${ }^{2}$, Marjan Ghazisaeedi ${ }^{3}$ \\ 'Department of Health Information Management, School of Management and Medical Information \\ Sciences, Shiraz University of Medical Sciences, Shiraz, Iran \\ ${ }^{2}$ Department of Medical Informatics, School of Management \& Medical Education Sciences, Shahid \\ Beheshti University of Medical Sciences, Tehran, Iran \\ ${ }^{3}$ Department of Health Information Management, School of Allied-Medical Sciences, Tehran University of \\ Medical Sciences, Tehran, Iran
}

Clinical decision support systems are interactive computer systems for situational decision making and can improve decision efficiency and safety of care. We investigated the role of these systems in enhancing prehospital care. This narrative review included full-text articles published since 2000 that were available in databases/e-journals including Web of Science, PubMed, Science Direct, and Google Scholar. Search keywords included "clinical decision support system," "decision support system," "decision support tools," "prehospital care," and "emergency medical services." Non-journal articles were excluded. We revealed 14 relevant studies that used such a support system in prehospital emergency medical service. Owing to the dynamic nature of emergency situations, decision timing is critical. Four key factors demonstrated the ability of clinical decision support systems to improve decision-making, reduce errors, and improve the safety of prehospital emergency activity: computer-based, offer support as a natural part of the workflow, provide decision support in the time and place of decision making, and offer practical advice. The use of clinical decision support systems in prehospital care resulted in accurate diagnoses, improved patient triage and patient outcomes, and reduction of prehospital time. By improving emergency management and rescue operations, the quality of prehospital care will be enhanced.

Keywords Decision support systems, clinical; Decision making; Emergency medical services

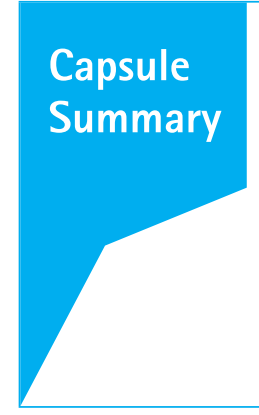

eISSN: 2383-4625

Received: 14 July 2018

Revised: 10 September 2018

Accepted: 12 October 2018

Correspondence to: Marjan Ghazisaeedi Department of Health Information Management, School of Allied Medical Sciences, Tehran University of Medical Sciences, No. 17, Farredanesh Alley, Ghods St, Enghelab Ave, Tehran 1417744361, Iran

E-mail:Ghazimar@tums.ac.ir ORCID

https://orcid.org/0000-0002-2400-209X

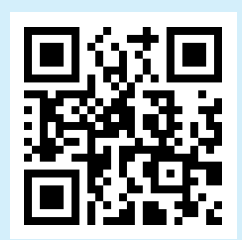

How to cite this article:

Bashiri A, Savareh BA, Ghazisaeedi M. Promotion of prehospital emergency care through clinical decision support systems: opportunities and challenges. Clin Exp Emerg Med 2019;6(4):288-296.

This is an Open Access article distributed under the terms of the Creative Commons Attribution Non-Commercial License (http:// creativecommons.org/licenses/by-nc/4.0/). 


\section{INTRODUCTION}

Prehospital emergency care comprises treatment that is provided to patients before they arrive at the hospital, including medical evaluation and care. ${ }^{1}$ In prehospital care, the focus is on the initial evaluation and supporting patients however possible., ${ }^{2,3}$ When prehospital emergency personnel reach an injured person, two types of strategic evaluations are performed to determine the patient's needs: a diagnostic analytical decision-making process (i.e., diagnostic rational behavior) and an interpretation of the patient's needs based on their health status (i.e., continuous care process). ${ }^{4}$ Prehospital personnel follow national emergency medical guidelines including protocols for emergency medical procedures and the treatment of specific symptoms and diagnostic groups. Depending on severity, the transfer time to a care facility differs; however, almost all emergency patients are transferred to an appropriate care hospital regardless of condition severity. ${ }^{1,45}$ Once a patient is transferred to an emergency department, prehospital personnel complete an electronic patient record detailing the situation, sterilize their equipment, and relinquish current responsibility for that patient. ${ }^{1}$

In general, the three tasks of emergency teams involve arriving at the scene, providing fast and effective treatment, and transferring the patient to the hospital. ${ }^{6}$ To accomplish these tasks, these care providers require access to updated information and knowledge. The importance of information technology to share information on disaster and emergency events is increasingly expanding and has vast potential to improve emergency medical response. ${ }^{7,8}$ In medicine, clinical decision support systems as are software programs designed to help the health professionals make decisions. These systems use data, models, and algorithms to make recommendations in the form of warnings, color codes, or picture messages to solve diagnostic, therapeutic, and organizational problems. Although these systems are not designed to replace humans, they can improve quality of care. Humans will inevitably make errors, and these systems are designed to help healthcare providers remember relevant diagnostic and treatment options, ${ }^{9-12}$ offer easy-to-follow instructions, reduce diagnostic and therapeutic errors, and change incorrect behaviors. ${ }^{13}$ In this study, we investigated the role of decision support systems in promoting prehospital care.

\section{METHODS}

This narrative review included searching full-text journal articles published since 2000 in databases and e-journals such as Web of Science, PubMed, Science Direct, and Google scholar. Search key-

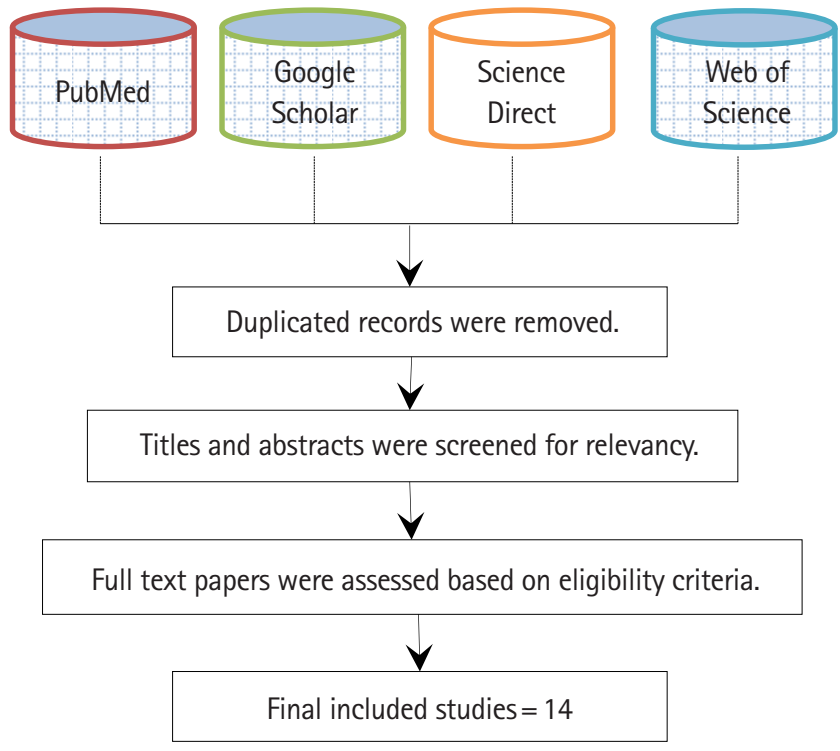

Fig. 1. The research methodology of study.

words included "clinical decision support system," "decision support system," "decision support tools," "prehospital care," and "emergency medical services." Non-journal articles were excluded. Overall, we identified 14 relevant studies that had used a clinical decision support system during prehospital emergency medical service. Fig. 1 shows the research methodology of this study.

Ethical issues (including plagiarism, misconduct, data fabrication and confidentiality, double publication and/or submission, redundancy, etc.) have been completely observed by the authors.

\section{RESULTS}

\section{Prehospital emergency medical services}

According to the National Board of Health and Welfare, prehospital emergency services are defined as medical care provided by healthcare professionals within or adjacent to the ambulance. ${ }^{14}$ The main objective of these services is to provide treatment to people who are in dire need of medical care and performing timely transfer to the nearest medical center. ${ }^{15}$ Prehospital services are represented by a symbolic star with six arms that comprise the following: early identification, early reporting, early response, optimization of care provided at the scene, care during transfer, and transporting to a definitive care center. ${ }^{16}$

\section{Types of prehospital trauma care systems}

Currently, there are four distinct types of prehospital trauma care systems: non-organized prehospital emergency care services, basic life support, advanced life support, and Doc-advanced life sup- 
port systems. ${ }^{15,17}$ In non-organized prehospital care that is seen in most developing countries, no organization is responsible for providing prehospital services to injured patients. In other words, there is no formal system for providing prehospital care and patients are sent to the medical center by the law forces. ${ }^{17}$ This type of care is offered especially in critical situations such as accidents involving public and private vehicles. ${ }^{17,18}$ Basic life support provides non-invasive support care of injured patients. This model represents a level of medical care to the victims of threatening illnesses or injuries until they can receive full medical care at the hospital. The main roles of emergency services in this model are the rapid delivery of the injured patient to healthcare centers and keeping them alive during the transition.

Non-health professionals who are present at the incident scene usually perform first aid or basic life support for victims and quickly inform emergency medical services. Basic life support skills depend on the availability of public education and instruction conducted in this field. ${ }^{18}$ Some developing countries and small cities and rural areas in developed countries follow this pattern. Advanced life support provides more complex care. In these systems, prehospital emergency teams receive special training programs for performing invasive procedures such as opening the airways and venous injections. ${ }^{16}$ The final model called Doc-advanced life support is advanced prehospital care; physicians are responsible for providing prehospital care of an injured person at the incident scene and during transport to the hospital. ${ }^{17}$

Emergency medical service systems may vary from a simple system that transfers the patient to a system that delivers acute medical care at the accident scene and during patient transfer to the hospital. In some parts of the world, emergency medical services transfer patients from one medical center to another medical institution with specialized services such as neonatal intensive care and pediatric intensive care, burn centers, spinal surgery or neurosurgery care institutions, regional stroke centers and specialized cardiac care, or transfer the patient to a local hospital or nursing home when the patient no longer requires specialized services, such as for the follow-up of cardiac catheterization for patients with myocardial infarction. ${ }^{15}$ Ambulance missions usually consist of seven stages, including a phone call and recording the address, reaching the location of the incident, performing assessments in place, performing an initial evaluation of the patient, transporting the patient to the ambulance, performing more treatment and evaluations on the way to the hospital, and delivery of the patient. ${ }^{19}$ Research indicates that the incident scene imposes much demand for judgment and decision-making by prehospital professionals. ${ }^{5}$ In addition to the uncertain environment, many factors result in gaps in judgment and the decision-making pro- cesses, including not being equipped with the right tools or having insufficient training to perform complex tasks. Other factors such as the lack of feedback, having dizziness and stress, and lack of motivation and morale also affect decision-making processes. ${ }^{20}$

\section{Challenges in prehospital medical services}

Globally, emergency care services face many challenges, including deficiencies in identification of emergency conditions, deviations from standard therapy, deterioration in the quality of medical care, increased costs due to unnecessary tests, and insufficient training of emergency personnel. ${ }^{21}$ On the other hand, an emergency situation is a serious incident that occurs without any warning; consequently, any defect in responding or delay in initial decision making can lead to serious injuries or even endanger the lives of people. $^{5}$ Prehospital care using clinical guidelines are a typical strategy to support prehospital care providers. Although several studies have shown low compliance of prehospital services with clinical guidelines, a possible way to increase compliance with these guidelines is the introduction of clinical decision support systems.

Hagiwara et al. ${ }^{22}$ reported the ability of clinical decision support systems in promoting compliance in prehospital emergency care with the evaluation process of emergency patients. Due to an increase in medical errors, providing safe and effective care is an ongoing challenge for clinicians. ${ }^{23}$ Therefore, the development of clinical guidelines to improve the quality of care and treatment outcomes and to reduce treatment costs by increasing the costbenefit ratio can be very effective. ${ }^{24}$ With these guidelines, clinical pathways and protocols can be electronically (in the form of decision support systems) used by physicians. ${ }^{25}$ Since prehospital care is part of clinical pathways, it imposes a lot of demands on the prehospital personnel for proper evaluation, indicating the necessity of decision support tools in prehospital care. ${ }^{23}$

\section{Clinical decision support systems in prehospital care} Clinical decision making is a complex process that can be regarded as a series of necessary decisions for observation and the best procedures to provide optimum care. The decision theory has four steps. The first phase consists of searching for information and data collection that can be obtained directly by a query from the patient or through various examinations. In the second phase, based on the information collected, a hypothesis is created. In the third phase, based on the assumptions made, the information is interpreted. Finally, in the fourth phase, the information is used to make decisions and a diagnosis. ${ }^{26,27}$

One of the most recognized models in decision-making is the dual-process theory. According to this theory, people have two distinct approaches to processing information for decision mak- 
ing: system 1 and system 2. System 1 processing is described as emotionally stimulated and ruled by habits. System 2 has been labeled analytical. It is used in situations that include uncertainty and poorly defined tasks. ${ }^{25}$ Andersen ${ }^{25}$ showed that this model provides a schematic overview of reasoning in dual-process theory. Decision making in emergency medical services emphasizes speed; therefore, Jones et al. ${ }^{28}$ proposed a medical decision making model in emergency medical services to describe how patients are evaluated in prehospital care, triage is applied, and the destination hospital is determined. Fig. 2 describes this model. ${ }^{28}$

Clinical decision support systems are an analytical tool that converts raw clinical data into useful information that helps physicians make better decisions about patients. These tools are often defined as electronic and non-electronic knowledge systems that use at least two objects of the patient data to make specific recommendations for the patient. ${ }^{23}$ The architecture of the clinical decision support system is shown elsewhere. ${ }^{29}$

The evolution of such systems has followed public innovation in technology and their capabilities have upgraded continuously from educational tools to intelligent systems for patient management. Decision support systems are designed to present knowledge in the form of algorithms, pathophysiological computational models, diagrams, Bayesian statistical systems, neural networks, fuzzy logic theory, and expert systems. ${ }^{29}$ Clinical decision support systems can be implemented in electronic medical records, warning physician in cases where there is inconsistency in the treatment program or when it is necessary to make changes to the patient's treatment based on discovered patterns in clinical data. ${ }^{23,25}$

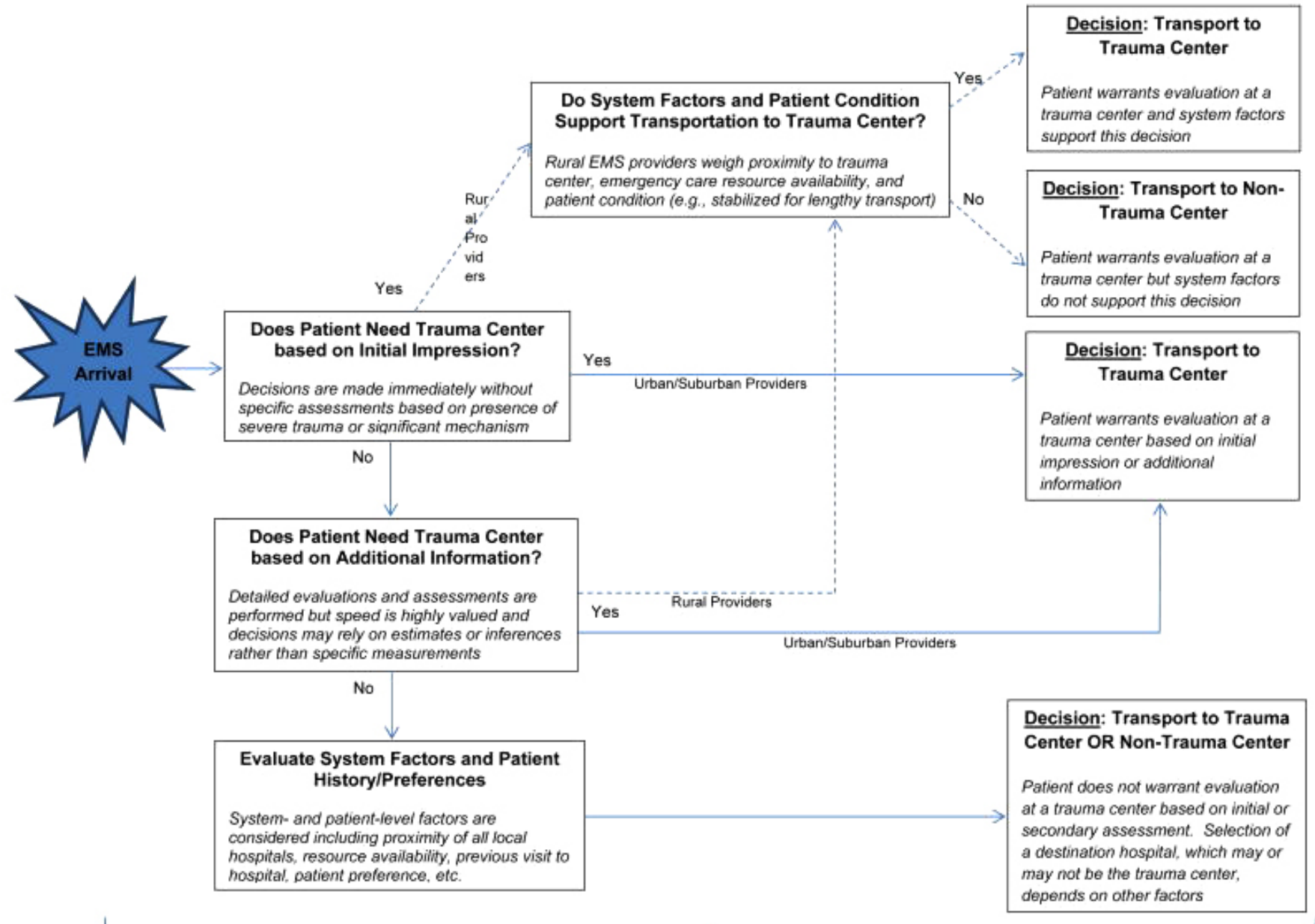

Familiarity with the Field Triage Decision Scheme influences which patient factors are assessed, but there is variability in its use. The decision process described by EMS providers places emphasis on speed and is non-linear and non-sequential, with multiple factors (e.g., blood pressure. consciousness, anatomic injuries, etc.) being evaluated concurrently, often relying on inferences, estimation, intuition, and prior experience.

Fig. 2. Decision model of triage for emergency medical service (EMS) providers. Repoduced from Jones CM, et al. Prehosp Emerg Care 2016;20:6-14, according to the Creative Commons Attribution License. ${ }^{28}$ 
Table 1. Decision support systems experience during prehospital emergency care

Sources (year) Purpose
Hagiwara et al. Develop and evaluate a CDSS for use in pre-hospital care
$(2014)^{22}$

Haghighi et al. Applying (development and evaluation) ontology to improve $(2013)^{32} \quad$ medical emergency decision-making.

Propose intelligent DSS architecture incorporating the ontology.

Vicente et al. Evaluate the feasibility and appropriateness of a prehospital sys$(2014)^{33} \quad$ tem to transport older adults to geriatric care

Salinas et al. Analyze the efficacy of a computerized open-loop decision sup$(2011)^{34} \quad$ port system for burn resuscitation compared to historical controls

Snooks et al. The evaluation of effectiveness, safety and cost-effectiveness of $(2014)^{35} \quad$ CCDS for paramedics attending older people who fall.

Gaynor et al. Explore the value of a dynamic data-driven application systems in $(2005)^{36} \quad$ support of emergency medical treatment decisions in response to a crisis.

Karlsten et al. Describe an information management system used in ambulances $(2000)^{37} \quad$ for data communication, documentation, triaging and presentation of checklists

Tian et al. Designing a mobile-based system to collect medical and temporal $(2014)^{38} \quad$ data produced during an emergency response to an $\mathrm{MCls}$

Acid et al. Propose using Bayesian networks to model the emergency medi$(2004)^{39} \quad$ cal service

Chang et al. Extend EMS personal digital assistant support systems to:

$(2004)^{40} \quad$ Cover pre-hospital EMS and onsite evaluation forms for the mass gatherings,

Evaluate users in terms of use and usefulness of the systems

Kovalchuk et Propose a conceptual model to integrate data with clinical DSS.

al. (2018) $)^{41}$ Develop a platform for data processing in decision making.

Describe a DSS within acute coronary system.

Derevitskiy et Propose the methodology for developing DSS in the ambulance al. $(2017)^{42}$ service

Yu et al. Improving $\mathrm{MCl}$ rescue efficiency

$(2018)^{43} \quad$ Providing a method of making rapid decisions during MCls

Hagiwara et al. Evaluate the effect of CDSS to increase patient safety in Prehos$(2011)^{44}$ pital care

\section{Results}

The developed and evaluated CDSS has the ability to:

Increase pre-hospital patient safety by reducing the risks of cognitive bias

Standardizing the assessment process

Enabling explicit decision support in the form of checklists

Assessment rules and differential diagnosis lists

Rule out worst-case scenario strategies

Reduces the risk of premature closure in the assessment of the prehospital patient

Construction and evaluation of DO4MG

Illustration of the application of the D04MG for implementation of a cased-based reasoning decision support for medical emergency management in mass gatherings.

DSS:

Empowers the ambulance nurses to triage older adults to an alternative healthcare facility

Optimizes resources and improve emergency care of elderly adults

CDSS:

Improves fluid management of severely burned patients

Reduces crystalloid fluid volume

Improves patients care.

The potential of CCDS to be cost-effective, especially with existing electronic data capture.

The decision support system enables coordinated decision-making by heterogeneous personnel across a wide geography at the same time.

Facilitating quality control and follow-up

Developed system has effectiveness in reducing overall mortality by an agent-based simulation model which has been established to simulate an emergency response to an $\mathrm{MCl}$

Developed a prototype for management decision support system

The usability of system for mass gatherings

The willingness of users to accept the system.

Developed platform supports data processing and resource management for acute coronary syndrome.

Developed model could analyze the time between the first contact of patient with surgical intervention

Decrease the mortality of $\mathrm{MCl}$

Shorten the prehospital time

Improve the efficiency of organization and command.

Improve the utilization rate of health resources.

CDSS increases the ambulance nurses' compliance with regional prehospital guidelines

CDSS, computerized decision support system; D04MG, domain ontology for mass gathering; DSS, decision support system; CCDS, computerized clinical decision support; $\mathrm{MCl}$, mass casualty incident; EMS, emergency medical service.

In designing a decision support system, parameters related to the technical infrastructure such as broadband, the tool's profile, and a complete history of interactions should be defined as a context of the effective performance in a dynamic environment. Several parameters such as geographic location, knowledge level, and skill of the specialists lead to differences in the knowledge and information requirements for decision support systems. The context is defined as a set of environmental features and conditions that determine the behavior of the system. The concept of decision support in the management of prehospital emergencies 
should provide full information according to the underlying model for decision makers. Since in time-critical decisions, the accuracy of the data considered in decision-making is essential to the overall quality of the result, the use of context modeling in the architecture of decision support leads to the creation of optimal decisions based on specific requirements. ${ }^{29,30}$ Ishak et al. ${ }^{5}$ offered a conceptual framework of intelligence for decision support systems: public specifications of emergency situations were identified and mapped with a natural decision-making model. They concluded that a decision support system should be suitable and user-friendly so that the structures and rules could be easily understood and all decisions could be replicated. Table 1 shows some studies about the application of decision support systems in prehospital emergency care. ${ }^{22,32-44}$

\section{DISCUSSION}

Emergency situations are dynamic and therefore require time-critical decisions. ${ }^{45-47}$ Emergency nurses make many decisions daily, which often affect the life and survival of patients. ${ }^{27}$ Factors such as the time of day, season and weather, the amount of time before other sources reach the scene, stress, patients' evaluation; and so on affect their response and decision. ${ }^{48,49}$ These factors and insufficient information lead to the complexity of the decision-making process.

Studies have also shown that when emergency nurses are called in emergency situations, the severity of the incident influences their decisions. In addition, experience is a key factor in decision making because experience leads to diverse competencies; specifically, the difference between novice and experienced nurses may be the interpretation of data, as novice nurses do not consider alternatives. ${ }^{26,27}$ Hence, to manage knowledge and support decisions, it is useful to collect and integrate nurses' experiences to present them in the form of a decision support system. ${ }^{32}$

Generally, clinical decision-making is a complex process; this process can be used to perform observations and determine what actions should be taken to provide optimal care. ${ }^{35}$ Since the failure to respond and making an early decision in emergency situations can lead to serious injury or even endanger the lives of patients, ${ }^{44,50,51}$ studies have revealed four key factors that demonstrate the ability of decision support systems to improve decision making, reduce errors, and increase prehospital clinical safety. The first factor is that decision support systems are computer-based. Per the second factor, these systems provide support as part of the natural workflow. Third, decision support systems are provided at the time and place of the decision making. Lastly, these systems offer practical advice. ${ }^{25,50}$ Thus, these systems were intro- duced to model and support the decision-making process. ${ }^{5}$

In prehospital care, decision support is defined as protocols, guidelines, and triage systems. The function and role of decision support data are to make an evaluation and specific recommendations for the patient and support all prehospital medical staff at all levels. ${ }^{23}$ In particular, the importance of decision support systems in emergency management is in activities such as the management of emergency medical care, risk reduction, and rescue and recovery operations. ${ }^{36,44}$ Many studies have shown the effectiveness of decision support tools in primary healthcare centers and hospitals and improved performance of healthcare workers and patients. ${ }^{11,12,51,52}$

In 2013, Vicente et al. ${ }^{53}$ reported that development of decision support systems in prehospital emergency care led to the facilitation of secure triage of elderly patients to the appropriate level of care. With the development of this system, nurses are empowered for secure decisions about the level of care and the needs of the elderly persons. There exists a need to integrate the aforementioned analytical and simulation models with the emergency medical services information system. ${ }^{54}$ The models become the analysis core of many decision support tools for emergency medical services. The work of Henderson and Mason ${ }^{55}$ was one of the efforts to combine simulation, a travel model, and geographic information system (GIS) into a decision support system for emergency medical services. Reduction in the required time to respond to an emergency is an essential goal of emergency medical services $^{54,56}$ The size and location of ambulances are two factors that directly affect response time. Repede and Bernardo ${ }^{56}$ developed a TIMEXCLP model (a maximal expected coverage location model with time variation) and integrated it with decision support systems to help ambulance teams in the assignment of vehicles. With the launch of this model in Louisville, Kentucky, the response time was reduced by $63 \% .{ }^{46}$ According to Derevitskiy et al. ${ }^{42}$ the decision support systems in the case of Acute Coronary Syndrome, can improve the time management in the ambulance service. In addition, Hagiwara et al. ${ }^{44}$ showed that the use of decision support tools during prehospital care reduced the time of patient transfer to a medical center and improved diagnostic accuracy.

Yu et al. ${ }^{43}$ showed that the development of decision support systems in emergency medical services can improve the efficiency of mass casualty incidents and provide a method for making rapid decisions during said incidents. Consistent with this study, Haghighi et al. ${ }^{32}$ and Tian et al. ${ }^{38}$ indicated that such systems are effective in reducing overall mortality in mass casualty incidents and management of mass gatherings. Further, Haghighi et al.,13 Vicente et al. ${ }_{1}^{33}$ and Salinas et al. ${ }^{34}$ focused on the ability of clinical decision support systems to empower prehospital nurses in 
the triage of patients and their compatibility with regional prehospital guidelines, optimize resources, and provide high quality care of elderly patients.

Moreover, Snooks et al..$^{35}$ and Karlsten and Sjoqvist ${ }^{37}$ noted the safety and cost-effectiveness of clinical decision support systems and the capability of such systems to facilitate quality control and follow-up in ambulances. Gaynor et al. ${ }^{36}$ and Chang et al. ${ }^{40} \mathrm{em}-$ phasized the capability of decision support systems to manage and coordinate decision making among various staff at the same time and the willingness of diverse users to apply it in the assessment of prehospital patients.

\section{CONCLUSION}

Generally, prehospital emergencies are characterized by judgment and decision making in uncertain situations. Physicians and prehospital specialists must make advanced decisions and evaluate and treat patients with various symptoms. Clinical decision support systems help users make decisions by using available resources, thus promoting effective decision-making and optimal medical emergency care. Clinical decision support systems in prehospital emergency care result in better triage of patients, reduced prehospital time, facilitate mass gathering management, optimize resources, increase diagnostic accuracy, improve patient outcomes, and enhance the quality of prehospital care.

\section{CONFLICT OF INTEREST}

No potential conflict of interest relevant to this article was reported.

\section{REFERENCES}

1. Vicente V. The use of a prehospital decision system in the emergency medical service: the acute chain for geriatric patients. Sodersjukhuset: Inst for Klinisk Forskning Och Utbildning; 2013.

2. Lyneham J, Parkinson C, Denholm C. Explicating Benner's concept of expert practice: intuition in emergency nursing. J Adv Nurs 2008;64:380-7.

3. Holmberg $M$, Fagerberg I. The encounter with the unknown: nurses lived experiences of their responsibility for the care of the patient in the Swedish ambulance service. Int J Qual Stud Health Well-being 2010;5:5098.

4. Elmqvist $\mathrm{C}$, Fridlund B, Ekebergh M. More than medical treatment: the patient's first encounter with prehospital emergency care. Int Emerg Nurs 2008;16:185-92.
5. Ishak W, Hussain W, Ku-Mahamud KR, Norwawi N. Conceptual framework for intelligent decision support system in emergency management [Internet]. Universiti Utara Malaysian Institutional Repository; 2010 [cited 2018 0ct 1]. Available from: http://repo.uum.edu.my/3468/.

6. Rahman AA, Zlatanova S. Pre-hospital location based services (LBS) for emergency management. In: Proceedings of Urban Data Management Symposium. Delft: Urban Data Management Society; 2006. p.11-49.

7. Levy G, Blumberg N, Kreiss Y, Ash N, Merin O. Application of information technology within a field hospital deployment following the January 2010 Haiti earthquake disaster. J Am Med Inform Assoc 2010;17:626-30.

8. Bellini P, Boncinelli S, Grossi F, Mangini M, Nesi P, Sequi L. Mobile emergency, an emergency support system for hospitals in mobile devices: pilot study. JMIR Res Protoc 2013;2:e19.

9. Legros B, Boon $P_{1}$ Ceulemans $B$, et al. Development of an electronic decision tool to support appropriate treatment choice in adult patients with epilepsy: Epi-Scope(R). Seizure 2012;21: 32-9.

10. Hemmerling TM. Decision support systems in anesthesia, emergency medicine and intensive care medicine [Internet]. [place unknown]: IntechOpen 2011 [cited 2018 0ct 1]. Available from: https://doi.org/10.5772/16957.

11. Ehtesham H, Safdari R, Mansourian A, et al. Clinical decision support system, a potential solution for diagnostic accuracy improvement in oral squamous cell carcinoma: a systematic review. J Oral Health Oral Epidemiol 2017;6:187-95.

12. Alizadeh B, Safdari R, Zolnoori M, Bashiri A. Developing an intelligent system for diagnosis of asthma based on artificial neural network. Acta Inform Med 2015;23:220-3.

13. Bates DW, Gawande AA. Improving safety with information technology. N Engl J Med 2003;348:2526-34.

14. Nilsson T, Lindstrom V. Clinical decision-making described by Swedish prehospital emergency care nurse students: an exploratory study. Int Emerg Nurs 2016;27:46-50.

15. Roudsari $B S$, Nathens $A B$, Cameron $P$, et al. International comparison of prehospital trauma care systems. Injury 2007;38: 993-1000.

16. Zatz A. The blue 'star of life': the emergency medical care symbol [Internet]. Oakland, CA: Alameda County Public Health Department; 1992 [cited 2018 Oct 1]. Available from: http:// m.acphd.org/media/154700/history_star_of_life.pdf.

17. Roudsari $B S$, Nathens $A B$, Arreola-Risa $C$, et al. Emergency Medical Service (EMS) systems in developed and developing countries. Injury 2007;38:1001-13.

18. Rea TD, Eisenberg MS, Becker $\amalg$, Murray JA, Hearne T. Tem- 
poral trends in sudden cardiac arrest: a 25-year emergency medical services perspective. Circulation 2003;107:2780-5.

19. Jensen J. Paramedic clinical decision-making: results of two Canadian studies. Int Paramed Pract 2011;1:63-71.

20. Brice JH, Studnek JR, Bigham BL, et al. EMS provider and patient safety during response and transport: proceedings of an ambulance safety conference. Prehosp Emerg Care 2012;16: 3-19.

21. Inokuchi $R$, Sato $H$, Nakajima $S$, et al. Development of information systems and clinical decision support systems for emergency departments: a long road ahead for Japan. Emerg Med J 2013;30:914-7.

22. Hagiwara MA, Suserud BO, Andersson-Gare B, Sjoqvist $B$, Henricson $M$, Jonsson $A$. The effect of a Computerised Decision Support System (CDSS) on compliance with the prehospital assessment process: results of an interrupted time-series study. BMC Med Inform Decis Mak 2014;14:70.

23. Jamal $A$, McKenzie $K$, Clark M. The impact of health information technology on the quality of medical and health care: a systematic review. Health Inf Manag 2009;38:26-37.

24. Damiani G, Pinnarelli L, Colosimo SC, et al. The effectiveness of computerized clinical guidelines in the process of care: a systematic review. BMC Health Serv Res 2010;10:2.

25. Andersen SE. Implementing a new drug record system: a qualitative study of difficulties perceived by physicians and nurses. Qual Saf Health Care 2002;11:19-24.

26. Gunnarsson BM, Warrén Stomberg M. Factors influencing decision making among ambulance nurses in emergency care situations. Int Emerg Nurs 2009;17:83-9.

27. Hicks FD, Merritt SL, Elstein AS. Critical thinking and clinical decision making in critical care nursing: a pilot study. Heart Lung 2003;32:169-80.

28. Jones CM, Cushman JT, Lerner EB, et al. Prehospital trauma triage decision-making: a model of what happens between the 9-1-1 call and the hospital. Prehosp Emerg Care 2016;20: 6-14.

29. Burstein F, Haghighi PD, Zaslavsky A, editors. Context-aware mobile medical emergency management decision support system for safe transportation. In: Schuff D, Paradice D, Burstein F, Power D, Sharda R. Decision support. New York, NY: Springer; 2011. p.163-81.

30. Dunsmuir D, Daniels J, Brouse C, Ford S, Ansermino JM. A knowledge authoring tool for clinical decision support. J Clin Monit Comput 2008;22:189-98.

31. Brigl B. Decision support, knowledge representation and management: a broad methodological spectrum. Findings from the Decision Support, Knowledge Representation and Man- agement. Yearb Med Inform 2006:81-3.

32. Haghighi PD, Burstein F, Zaslavsky A, Arbon P. Development and evaluation of ontology for intelligent decision support in medical emergency management for mass gatherings. Decis Support Syst 2013;54:1192-204.

33. Vicente V, Svensson L, Wireklint Sundstrom B, Sjostrand F, Castren M. Randomized controlled trial of a prehospital decision system by emergency medical services to ensure optimal treatment for older adults in Sweden. J Am Geriatr Soc 2014; 62:1281-7.

34. Salinas J, Chung KK, Mann EA, et al. Computerized decision support system improves fluid resuscitation following severe burns: an original study. Crit Care Med 2011;39:2031-8.

35. Snooks HA, Carter B, Dale J, et al. Support and Assessment for Fall Emergency Referrals (SAFER 1): cluster randomized trial of computerised clinical decision support for paramedics. PLoS One 2014;9:e106436.

36. Gaynor M, Seltzer M, Moulton S, Freedman J. A dynamic, data-driven, decision support system for emergency medical services. In: Sunderam VS, van Albada GD, Sloot PM, Dongarra $J$ J, editors. Computational Science: International Conference on Computational Science 2005. Berlin: Springer; 2005. p.70311.

37. Karlsten R, Sjoqvist BA. Telemedicine and decision support in emergency ambulances in Uppsala. J Telemed Telecare 2000; 6:1-7.

38. Tian Y, Zhou TS, Yao Q, Zhang M, Li JS. Use of an agent-based simulation model to evaluate a mobile-based system for supporting emergency evacuation decision making. J Med Syst 2014;38:149.

39. Acid S, de Campos LM, Fernandez-Luna JM, Rodriguez S, Maria Rodriguez J, Luis Salcedo J. A comparison of learning algorithms for Bayesian networks: a case study based on data from an emergency medical service. Artif Intell Med 2004;30:21532.

40. Chang P, Hsu YS, Tzeng YM, Sang YY, Hou IC, Kao WF. The development of intelligent, triage-based, mass-gathering emergency medical service PDA support systems. J Nurs Res 2004; 12:227-36.

41. Kovalchuk SV, Krotov E, Smirnov PA, Nasonov DA, Yakovlev AN. Distributed data-driven platform for urgent decision making in cardiological ambulance control. Future Gener Comput Syst 2018;79:144-54.

42. Derevitskiy I, Krotov E, Voloshin D, Yakovlev A, Kovalchuk SV, Karbovskii V. Simulation of emergency care for patients with ACS in Saint Petersburg for ambulance decision making. Procedia Comput Sci 2017;108:2210-9. 
43. Yu W, Lv Y, Hu C, et al. Research of an emergency medical system for mass casualty incidents in Shanghai, China: a system dynamics model. Patient Prefer Adherence 2018;12:20722.

44. Hagiwara $M$, Henricson $M$, Jonsson $A$, Suserud BO. Decisionsupport tool in prehospital care: a systematic review of randomized trials. Prehosp Disaster Med 2011;26:319-29.

45. Thompson SM, Altay N, Green III WG, Lapetina J. Improving disaster response efforts with decision support systems. Int J Emerg Manag 2006;3:250-63.

46. Mahapatra S, Koelling CP, Patvivatsiri L, Fraticelli B, Eitel D, Grove L. Emergency departments II: pairing emergency severity index5-level triage data with computer aided system design to improve emergency department access and throughput. In: WSC 2003 Proceedings of the 35th conference on Winter simulation: driving innovation. 2003 Dec 7-10; New Orleans, LA, USA. New York, NY: Association for Computing Machinery; 2003. p.1917-25.

47. Skyttberg N, Vicente J, Chen R, Blomqvist $H$, Koch S. How to improve vital sign data quality for use in clinical decision support systems? A qualitative study in nine Swedish emergency departments. BMC Med Inform Decis Mak 2016;16:61.

48. Sujanto F, Burstein F, Ceglowski A, Churilov L. Application of domain ontology for decision support in medical emergency coordination. In: Proceedings of the Fourteenth Americas Conference on Information Systems; 2008 Aug 14-17; Toronto, Canada. [place unknown]: Americas Conference on Informa- tion Systems; 2008. p.33.

49. Wireklint Sundstrom B, Dahlberg K. Caring assessment in the Swedish ambulance services relieves suffering and enables safe decisions. Int Emerg Nurs 2011;19:113-9.

50. Mechem CC, Goodloe JM, Richmond NJ, Kaufman BJ, Pepe PE; U.S. Metropolitan Municipalities EMS Medical Directors Consortium. Resuscitation center designation: recommendations for emergency medical services practices. Prehosp Emerg Care 2010;14:51-61.

51. Kawamoto K, Houlihan CA, Balas EA, Lobach DF. Improving clinical practice using clinical decision support systems: a systematic review of trials to identify features critical to success. BMJ 2005;330:765.

52. Bashiri A. Application of artificial neural network technique for diagnosing asthma. Int Sch Sci Res Innov 2016;10:1.

53. Vicente V, Sjostrand F, Sundstrom BW, Svensson L, Castren M. Developing a decision support system for geriatric patients in prehospital care. Eur J Emerg Med 2013;20:240-7.

54. Brotcorne L, Laporte G, Semet F. Ambulance location and relocation models. Eur J Oper Res 2003;147:451-63.

55. Henderson SG, Mason AJ. Ambulance service planning: simulation and data visualisation. In: Pierskalla WP, Sainfort F. Operations research and health care: a handbook of methods and applications. Boston: Springer; 2005. p.77-102.

56. Repede JF, Bernardo JJ. Developing and validating a decision support system for locating emergency medical vehicles in Louisville, Kentucky. Eur J Oper Res 1994;75:567-81. 